American Journal of Immunology 5 (4): 108-112, 2009

ISSN 1553-619X

(C) 2009 Science Publications

\title{
Evaluation of Anti-Tetanus Immunity in Haemodialysis Patients
}

\author{
${ }^{1}$ Abdolreza Sotoodeh Jahromi, ${ }^{2}$ Rahim Raoofi, ${ }^{3}$ Marzieh Sarikhani and ${ }^{4}$ Abdolhossain Madani \\ ${ }^{1}$ Department of Immunology, Jahrom University of Medical Science, Jahrom, Iran \\ ${ }^{2}$ Department of Infection Diseases, Jahrom University of Medical Science, Jahrom, Iran \\ ${ }^{3}$ Student Research Committee, Jahrom University of Medical Science, Jahrom, Iran \\ ${ }^{4}$ Department of Hygiene, Hormozgan University of Medical Science, Bandar Abbas, Iran
}

\begin{abstract}
Problem statement: The incidence of infectious diseases is increased in patients with chronic renal failure. Chronic renal failure severely influences the immune functions of the host. Approach: To evaluate the antitetanus immunity level in southern Iranian patients with end stage renal disease undergoing hemodialysis and to find its association with sex, age, blood hemoglobin and serum albumin, duration of dialysis. This cross sectional study was carried out on a total of 52 patients, who were on hemodialysis and 52 age and sex matched healthy individuals with without any underlying renal disease as a control group. Individuals in the both groups receiving antitetanus toxoid vaccine or immunoglubins a year prior to the study were excluded. The serum antitetanus $\operatorname{IgG}$ antibody levels were measured by an ELISA method. Results: Tetanus protected individuals in the patients and the control groups were 34.6 and $63.30 \%$ respectively. Of the evaluating factors just hemodialysis duration found to affect on tetanus immunity. Conclusion: Tetanus protected individuals in the patients group were significantly less than tetanus protected individuals in the control group $(p=0.011)$. Hemodialysis duration has significant effect on antitetanus immunity level.
\end{abstract}

Key words: Antitetanus immunity, hemodialysis, chronic renal failure

\section{INTRODUCTION}

Infectious diseases are the leading cause of death in End-Stage Renal Disease (ESRD) patients, second only to cardiovascular disease. They also contribute to a significant morbidity in patients with earlier stages of Chronic Kidney Disease (CKD) $)^{[1]}$.

The incidence of infectious diseases is increased in patients with chronic renal failure ${ }^{[2]}$. This is thought to be due to an immunosupressed status in this population $^{[3-7]}$. This is thought to be related to an impaired $\mathrm{T}$ cell activation by antigen presenting cells ${ }^{[8]}$, impaired immune Responses and Antigen-Specific Memory CD4+ $\mathrm{T}$ Cells ${ }^{[5]}$, impaired monocyte and monocyte-derived dendritic cell function ${ }^{[4]}$, defects in NK cell function ${ }^{[6]}$, immunodeficiency status manifested decrease in the number of CD3+, CD4+ and CD72+ cells and phagocytosis intensification ${ }^{[7]}, \mathrm{T}$ and B-lymphocyte abnormalities and impaired responses to $\mathrm{T}$ cell dependent pathogens such as hepatitis B virus $^{[9-13]}$. Tetanus toxoid is an antigen known to induce strong $\mathrm{T}$ cell specific immune responses in humans after vaccination ${ }^{[14]}$.
In many countries, non-neonatal tetanus is still a significant public health problem, particularly among children, adolescents and young adults ${ }^{[15]}$.

Although the vaccination against tetanus has significantly decreased the disease after infection with Clostridium tetani ${ }^{[16]}$, recent epidemiologic studies indicate that the number of insufficiently protected individuals has increased especially in the elderly ${ }^{[17,18]}$.

In 2004, WHO and UNICEF reported the incidence of diphtheria, tetanus and pertussis in Iran to be 6, 11 and 98 cases, respectively while in 2005 , the respective incidences were 15,8 and $125^{[19,20]}$.

The age of Iranian patients with tetanus, was reported $45-60$ years, in which $71.4 \%$ of patients were farmers or dairy workers ${ }^{[21]}$.

Vaccination is the most effective means of preventing infectious diseases. Immunization programs are of great importance in the prevention of infectious diseases in immunocompromised individuals. However, the immune response to various vaccinations is impaired in patients with chronic renal failure ${ }^{[16]}$, requiring multiple boosts to generate a robust protective response (e.g., hepatitis $\mathrm{B}$, diphtheria, pertussis and tetanus) ${ }^{[22-24]}$.

Corresponding Author: Abdolreza Sotoodeh Jahromi, Department of Immunology, Jahrom University of Medical Science, Jahrom, Iran Tel: +989173910200 Fax: +987913341509 
The tetanus, diphtheria and pertussis vaccination programme in Iran has been running since 1950 using a local vaccine manufactured by Razi Institute (RaziDTwP), Tehran, Iran and the efficacy of the vaccine was confirmed by previous studies ${ }^{[25,26]}$, but there is no routine vaccination for hemodialysis patients and So far only a few studies have focused on seroresponse to tetanus toxoid in these patients in $\operatorname{Iran}^{[27]}$.

\section{MATERIALS AND METHODS}

Subjects: This cross sectional study was carried out on a total of 52 patients ( 36 men and 16 women), with a mean age of $57.75 \pm 14.26$ years, who were on hemodialysis due to end-stage renal disease in the Hemodialysis Center of Jahrom University of Medical Sciences in 2009. Fifty two healthy individuals (35 men and 17 women) with normal ceratinine and BUN and without any underlying renal disease with a mean age of $58.98 \pm 14.32$ as a control group were enrolled in this research.

There were not significant differences between age $(p=0.912)$ and $\operatorname{sex}(p=0.112)$ in the cases and the controls.

As there were not data indicating past history of vaccination in both groups, the control group was randomly selected among the same community of patients group to increase the reliability of the results. Individuals in the both groups receiving antitetanus toxoid vaccine or immunoglubins a year prior to the study were excluded.

Data collection: Data including sex, age, hemoglobin, serum albumin, duration of dialysis, Body Mass Index (BMI) were obtained from all of the hemodialysis patients and their medical records.

Serologic evaluations: Antitetanus toxoid IgG level was determined on serum samples taken from patients before starting hemodialysis. Sera were separated and stored at $-70^{\circ} \mathrm{C}$ until analysis. Antibody levels were measured by commercial ELISA kits (IBL-Hamburg GmbH, Hamburg, Germany). Optical density was measured at $450 \mathrm{~nm}$ using ELISA reader (Awerness Instruments, USA). Based on the EPI Program of WHO, the assay cut-offs for protective level of tetanus antibody was set at 0.1 International Units (IU $\mathrm{mL}^{-1}$ ) (14). Concentrations above the assay cut-offs were considered to be seroprotective.

Ethics: The study was approved by the ethics committee of Jahrom University of Medical Sciences.

Statistical analysis: Statistical analyses were performed using SPSS ver.16 software (SPSS Inc.,
Chicago, Illinois) Statistical differences of various clinical and laboratory parameters between groups were evaluated by Chi-Square or Mann-Whitney U tests. To compare the means of two groups, the two independent sample t-tests were used. p-values of less than 0.05 were considered significant.

\section{RESULTS}

The mean serum antitetanus IgG level of hemodialysis patients was $0.099 \pm 0.073 \mathrm{Vs}$ $0.560 \pm 0.719 \mathrm{IU} \mathrm{mL}^{-1}$ in the control group $(\mathrm{p}=0.001)$.

The patients and the control groups were divided into 3 groups by their antitetanus IgG level:

Group 1: $\operatorname{IgG}<0.1 \mathrm{IU} \mathrm{mL}^{-1}$ which are not protective and need basic immunization through tetanus booster vaccine.

Group 2: About $0.1<\mathrm{IgG}<1 \mathrm{IU} \mathrm{mL}^{-1}$ who need to be controlled in 1-2 years and group 3: $1<\mathrm{IgG}<5 \mathrm{IU} \mathrm{mL}^{-1}$ who need to be controlled in 2 to 4 years. Therefore 34 $(65.40 \%)$ patients were not protected against tetanus because their IgG less than $0.1 \mathrm{IU} \mathrm{mL}^{-1[17]}$. Table 1 illustrates the characteristics of the patients and the control groups.

Among the contributing factors studied, only the patients with longer duration of hemodialysis had lower antitetanus IgG level ( $\mathrm{p}=0.05)$.

It is also noteworthy that patients with the highest antitetanus IgG and immunization against tetanus (level 3 ) have the shortest duration of dialysis $(p=0.03)$ (Table 2).

Table 1: Comparison of the characteristics of patients and control

\begin{tabular}{|c|c|c|c|}
\hline Variables & $\begin{array}{l}\text { Hemodialysis } \\
\text { patients }\end{array}$ & Control group & p-value \\
\hline$\overline{\text { Age (years) }}$ & $57.75 \pm 14.26$ & $58.98 \pm 14.32$ & $\mathrm{p}=0.900$ \\
\hline \multirow[t]{2}{*}{ Gender } & $\begin{array}{l}36(69.23 \%) \\
\text { men }\end{array}$ & $\begin{array}{l}35(67.30 \%) \\
\text { men }\end{array}$ & \\
\hline & $\begin{array}{l}16(30.77 \%) \\
\text { women }\end{array}$ & $\begin{array}{l}17(32.70 \%) \\
\text { women }\end{array}$ & $\mathrm{p}=0.900$ \\
\hline $\begin{array}{l}\text { Antitetanus } \mathrm{IgG} \\
\text { (IU mL } \mathrm{mL}^{-1} \text { ) }\end{array}$ & $0.099+0.073$ & $0.560+0.719$ & $\mathrm{p}=0.001$ \\
\hline Level of protection & $18(34.60 \%)$ & $33(63.30 \%)$ & $\mathrm{p}=0.011$ \\
\hline
\end{tabular}

Table 2: Comparison of the characteristics of protected patients (group 2 and 3)

\begin{tabular}{llll}
\hline $\begin{array}{l}\text { Factors affecting } \\
\text { anti tetanus IgG }\end{array}$ & Level 2 (12 patients) & Level 3 $(6$ patients $)$ & p-value \\
\hline Age (years) & $48.7 \pm 13.6$ & $51.2 \pm 10.3$ & 0.84 \\
BMI & $25.7 \pm 4.3$ & $24.2 \pm 5.9$ & 0.69 \\
Albumin $\left(\mathrm{g} \mathrm{dL}^{-1}\right)$ & $4.2 \pm 0.64$ & $4.8 \pm 0.79$ & 0.41 \\
$\mathrm{Hb}\left(\mathrm{g} \mathrm{dL}^{-1}\right)$ & $8.8 \pm 1.7$ & $8.6 \pm 1.4$ & 0.71 \\
$\begin{array}{l}\text { Duration of } \\
\text { hemodialysis (weeks) }\end{array}$ & $28.65 \pm 22.35$ & $14.84 \pm 24.34$ & 0.03 \\
\hline
\end{tabular}




\section{DISCUSSION}

The immunodeficiency in patients with chronic renal failure makes them prone to more fatal outcomes of infectious diseases. A few studies were done on immunization against tetanus in patients with chronic renal failure ${ }^{[28-33]}$.

Tetanus protected individuals in the patients group were significantly less than tetanus protected individuals in the control group (34.6 Vs $63.30 \%)$ $(\mathrm{p}=0.011)$.

Sagheb et al. ${ }^{[16]}$ reported $74.3 \%$ of patients were unprotected against tetanus compared with $52.8 \%$ of the control group, his results and our results approximately are the same.

Kruger $e$ e $a l{ }^{[16]}$ showed that out of 71 patients with chronic hemodialysis only $31(44 \%)$ were protected against tetanus while the rate in healthy control group was 8 out of 9 (89\%), therefore, appeared that hemodialysis patients' and healthy individuals' susceptibility to tetanus is much higher in our study compared to their report.

In Kruger's investigation, the proportion of protected patients was larger in males compared to females and the same results was found in our study, $23.08 \%$ of men and $11.50 \%$ of women out of patient group were protected, while in Sageb's investigation, the proportion of protected patients was larger in females compared to males but without any statistical significance ${ }^{[16]}$.

The mean serum antitetanus IgG level of the hemodialysis patients was significantly lower than the mean serum antitetanus IgG level in the control group $(\mathrm{p}=0.001)$. We found a significant negative effect by the duration of hemodialysis on antitetanus IgG level in our patients group $(\mathrm{p}=0.03)$ and we did not find any significant effect by the other contributing factors on antitetanus IgG level in either chronic hemodialysis or in the all hemodialysis patients. Also there was not statistically meaningful difference between the protected against tetanus patients $(\mathrm{n}=18)$ and those not protected $(\mathrm{n}=34)$. Such results were showed by Sagheb et al. ${ }^{[16]}$.

According to Guerin et al. ${ }^{[34]}$ results indicating rapid decline in the titer of antitetanus $\operatorname{IgG}$ in vaccinated hemodialysed patients who had a protected status after 6 months, among the different factors considered, only age significantly impaired or reduced the immune response.

\section{CONCLUSION}

To conclude, it seems that most of our hemodialysis patients need booster tetanus vaccine to increase their antitetanus immunity. We suggest frequent monitoring of antibody levels after immunization against tetanus in hemodialysis patients.

\section{ACKNOWLEDGEMENT}

This study was completely financed by Student Research Committee (SRC) of Jahrom University of Medical Sciences. The authors are grateful to the patients and the control individuals who accepted to enter this study. This article has been extracted from Ms Sarikhani's thesis.

\section{REFERENCES}

1. Kausz, A.T. and D.T. Gilbertson, 2006. Overview of vaccination in chronic kidney disease. Adv. Chronic Kidney Dis., 13: 209-214. http://www.ncbi.nlm.nih.gov/pubmed/18065804

2. Koehler, H., Girndt Mr., H. Dumann and R. Klingel, 1993. Immun defekt bei Niereninsuffizienz. Deutsche medizinische Wochenschrift, 118: 790-795.

3. Dinits-Pensy, M., G.N. Forrest, A.S. Cross and M.K. Hise, 2005. The use of vaccine in Adult patients with renal disease. Am. J. Kidney Dis., 46: 997-1011. DOI: 10.1053/j.ajkd.2005.08.032

4. Lim, W.H., S. Kireta, E. Leedham, G.R. Russ and P.T. Coates, 2007. Uremia impairs monocyte and monocyte-derived dendritic cell function in hemodialysis patients. Kidney Int., 72: 1138-1148. http://cat.inist.fr/?aModele $=$ afficheN\&cpsidt $=1921$ 0927

5. Litjens, N.H., M. Huisman, M. van den Dorpel and M.G. Betjes, 2008. Impaired immune responses and antigen-specific memory $\mathrm{CD} 4+\mathrm{T}$ cells in hemodialysis patients. J. Am. Soc. Nephrol., 19: 1483-1490.

http://www.ncbi.nlm.nih.gov/pubmed/18480314

6. Vacher-Coponat, H., C. Brunet, L. Lyonnet, E. Bonnet and A. Loundou et al., 2008. Natural killer cell alterations correlate with loss of renal function and dialysis duration in uraemic patients. Nephrol. Dial. Transplant., 23: 1406-1414. PMID: 18029366

7. Kaliuzhina, E.V., O.A. Geĭnits, V.V. Kaliuzhin and Pak IuD., 2006. The condition of immune homeostasis in patients with chronic renal failure. Klin. Med. (Mosk), 84: 60-63. PMID: 17243614

8. Girndt, M., H. Köhler, E. Schiedhelm-Weick, K.H. Meyer Zum Büschenfelde and B.T. Fleischer, 1993. T-cell activation defect in hemodialysis patients: Evidence for a role of the B7/CD28 pathway. Kidney Int., 44: 359-365. http://www.ncbi.nlm.nih.gov/pubmed/7690861 
9. Rendi-Wagner, P., M. Kundi, H. Stemberger, G. Wiedermann, H. Holzmann and M. Hofer, 2001. Antibody-response to three recombinant hepatitis B vaccines: Comparative evaluation multicenter travel-clinic based experience. Vaccine, 19: 2055-2060. http://www.ncbi.nlm.nih.gov/pubmed/11228377

10. Slusarczyk, Y., 2002. Who needs vaccination on against hepatitis B viruses? Vaccine, 18: 54-55.

11. Bonanni, P., 1998. Universal hepatitis B immunization: Infant and infant plus adolescent immunization. Vaccine, 16: 17-22. http://www.ncbi.nlm.nih.gov/pubmed/9915027

12. Koff, R.S., 2002. Immunogenicity of hepatitis B vaccines: Implications of immune memory. Vaccine, 20: 3695-3701. http://www.ncbi.nlm.nih.gov/pubmed/12399197

13. Argani, H. and E. Akhtarishojaie, 2006. Levamizole enhances immune responsiveness to intra-dermal and intra-muscular hepatitis B vaccination in chronic hemodialysis patients. J. Immun. Based Ther. Vaccines, 4: 3. http://www.ncbi.nlm.nih.gov/pmc/articles/PMC154 0413/

14. Mayer, S., M. Laumer, A. Mackensen, R. Andreesen and S.W. Krause, 2002. Analysis of the immune response against tetanus toxoid: Enumeration of specific $\mathrm{T}$ helper cells by the Elispot assay. Immunobiology, 205: 282-289. http://www.ncbi.nlm.nih.gov/pubmed/12182454

15. WHO., 2006. Relevé épidémiologique hebdomadaire. Weekly Epidemiolog. Rec., 81: 197-208. http://www.who.int/wer/2006/wer8120.pdf

16. Krüger, S., M. Seyfarth, K. Sack and B. Kreft, 1999. Defective immune response to tetanus toxoid in hemodialysis patients and its association with diphtheria vaccination. Vaccine, 17: 1145-1150. http://www.ncbi.nlm.nih.gov/pubmed/10195626

17. Klouche, M., S. Görg, D. Wilhelm and H. Kirchner, 1994. Sex and age-dependent gaps in tetanus immunization. Dtsch. Med. Wochenschr, 119: 827-832.

http://www.ncbi.nlm.nih.gov/pubmed/8005053

18. Gergen, P.J., G.M. McQuillan, M. Kiely, T.M. Ezzati-Rice, R.W. Sutter and G. Virella, 1995. A population-based serologic survey of immunity to tetanus in the United States. N. Engl. J. Med., 332: 761-766. http://www.ncbi.nlm.nih.gov/pubmed/7862178

19. UNICEF., 2006. Immunization summary. http://www.unicef.org/publications/files/Immunizat ion_Summary_2006.pdf
20. WHO., 2006. Immunization summary. http://www.who.int/vaccinesdocuments/GlobalSu mmary/GlobalSummary.pdf

21. Vahdani, P. and Z. Amin Zadeh, 2003. Epidemiologic survey and clinical manifestation of Tetanus disease for 9 years (1370-79) in Loghman Hospital. Iran. J. Infect. Dis. Trop. Med., 22: 56-54.

22. Trollfors, B., N. Knutsson, J. Taranger, A. Mark, E. Bergfors and V. Sundh et al., 2006. Diphtheria, tetanus and pertussis antibodies in 10-year-old children before and after a booster dose of three toxoids: Implications for the timing of a booster dose. Eur. J. Pediatr., 165: 14-18. DOI: 10.1007/s00431-005-1763-3

23. Storsaeter, J. and J. Wolter, 2006. Is there a need for a new generation of vaccines against pertussis? Expert Opin. Emerg. Drugs, 11: 195-205. DOI: 10.1517/14728214.11.2.195

24. Skowera, A., E.C. de Jong, J.H. Schuitemaker, J.S. Allen, S.C. Wessely and G. Griffiths et al., 2005. Analysis of anthrax and plague biowarfare vaccine interactions with human monocyte-derived dendritic cells. J. Immunol., 175: 7235-7243. http://cat.inist.fr/?aModele $=$ afficheN\&cpsidt $=17292103$

25. Mirchamcy, H., 1960. Study on diphtheria, tetanus combined immunization in children in some elementary school of Tehran. Arch. Inst. Razi., 12: 9-18.

26. Zarei, S., M. Jeddi-Tehrani, M.M. Akhondi, H. Zeraati, T. Kheirkhah and M. Ghazanfari, 2007. Immunogenicity of a triple diphtheria-tetanuswhole cell Pertussis vaccine in Iranian preschool children. Iran J. Immunol., 4: 101-109. http://www.ncbi.nlm.nih.gov/pubmed/17652850

27. Sagheb, M.M., Sajjadi Sh and G. Sajjady, 2008. Antitetanus toxoid antibody titer of chronic hemodialysis patients in Iran. Iran J. Immunol., 5: 45-50. http://www.ncbi.nlm.nih.gov/pubmed/18319524

28. Krüger, S., M. Müller-Steinhardt, H. Kirchner and B. Kreft, 2001. A 5 year follow-up on antibody response after diphtheria and tetanus vaccination in hemodialysis patients. Am. J. Kidney Dis., 38: 1264-1270.

http://linkinghub.elsevier.com/retrieve/pii/S027263 8601496818

29. Kreft, B., A. Fischer, S. Krüger, K. Sack, H. Kirchner and L. Rink, 2000. The impaired immune response to diphtheria vaccination in elderly chronic hemodialysis patients is related to zinc deficiency. Biogerontology, 1: 61-66. http://www.ncbi.nlm.nih.gov/pubmed/11707922 
30. Girndt, M., M. Pietsch and H. Köhler, 1995. Tetanus immunization and its association to hepatitis B vaccination in patients with chronic renal failure. Am. J. Kidney Dis., 26: 454-460. http://cat.inist.fr/?aModele $=$ afficheN\&cpsidt $=3691$ 498

31. Kleinknecth, C., A. Margolis, C. Bonnissol, M. Gaiffe, S. Sahyoun and M. Broyer, 1977. Serum antibodies before and after immunisation in haemodialysis children. Proc. Eur. Dial. Transplant. Assoc., 14: 209-214.

32. McCusker, C., W. Somerville, V. Grey and B. Mazer, 1997. Specific antibody responses to diphtheria/tetanus revaccination in children evaluated for immunodeficiency. Ann. Allergy Asthma Immunol., 79: 145-150. http://www.ncbi.nlm.nih.gov/pubmed/9291419
33. Enke, B.U., A. Bökenkamp, G. Offner, P. Bartmann and J. Brodehl, 1997. Response to diphtheria and tetanus booster vaccination in pediatric renal transplant recipients. Transplantation, 64: 237-241. http://cat.inist.fr/?aModele $=$ afficheN\&cpsidt $=2776$ 258

34. Guerin, A., Y. Buisson, M.T. Nutini, P. Saliou, G. London and S. Marchais, 1992. Response to vaccination against tetanus in chronic haemodialysed patients. Nephrol. Dial. Transplant., 7: 323-326.

http://www.ncbi.nlm.nih.gov/pubmed/1317523 